\title{
A COBRANÇA DE HONORÁRIOS POR CORRETORES DE IMÓVEIS EM AVALIAÇÕES IMOBILIÁRIAS PARA FINS DE PERÍCIA
}

\section{ARTIGO ORIGINAL}

LIMA, Mario Sergio Torres Fontes ${ }^{1}$

LIMA, Mario Sergio Torres Fontes. A cobrança de honorários por corretores de imóveis em avaliações imobiliárias para fins de perícia. Revista Científica Multidisciplinar Núcleo do Conhecimento. Ano 05, Ed. 08, Vol. 15, pp. 54-65. Agosto de 2020.

ISSN:

2448-0959,

Link

de

acesso: https://www.nucleodoconhecimento.com.br/lei/cobranca-de-honorarios

\section{RESUMO}

O artigo aborda a questão da cobrança de honorários periciais a serem cobrados pelo corretor de imóveis quando atua como perito avaliador. De acordo com a temática buscou-se explicar quais as atribuições dos peritos e mecanismos de elaboração de laudos técnicos periciais em avaliação imobiliária, observando a complexidade que o assunto impõe e assim compreender a cobrança de honorários periciais por parte do profissional de corretagem. A metodologia utilizada na pesquisa foi a revisão bibliográfica, utilizando livros, artigos e sites que tratem do tema proposto, além da análise de jurisprudência nacional que tenha a temática como questão a ser decidida. O objetivo do estudo foi identificar e compreender como o perito avaliador pode definir o valor de seus honorários e a justificativa para essa cobrança.

Palavras-chaves: Honorários, laudo, avaliação, perícia, imóveis.

\footnotetext{
${ }^{1}$ Graduado em Gestão da Tecnologia da Informação pela universidade Tiradentes, Perito Judicial em Avaliações Imobiliárias.
} 


\section{INTRODUÇÃO}

As constantes modificações no mercado imobiliário passaram por agregar novas funções aos corretores de imóveis, funções estas que anteriormente não correspondiam às atuações deste profissional que comumente vendiam ou locavam propriedades. Diante das constantes modificações que assolam as economias, o mercado imobiliário se tornou mais largo e assim os profissionais do ramo da corretagem de imóveis passaram a ser solicitados para a realização de consultorias jurídicas, vistorias e avaliações, além de perícias que buscam solucionar problemas decorrentes da execução do contrato de compra e venda de imóveis.

Cumpre destacar que atribuição da função de avaliar imóveis requer do corretor de imóveis estudo, planejamento e conhecimento das normas técnicas que norteiam essa atividade, isso se deve ao fato de que definir um valor pecuniário à um imóvel é uma atividade complexa que deve levar em considerações diversos aspectos, e essa é a meta do avaliador perito, buscar identificar os melhores valores para aluguel, compra e venda, garantia de hipoteca, herança, valores fiscais entre outros.

Diante desse cenário há que se entender a importância desse estudo, afinal a atuação do corretor de imóveis como perito avaliador exige profundo conhecimento do mercado imobiliário e o conhecimento especializado na função de perito, nesse sentido o objetivo da pesquisa é destacar os aspectos técnicos da função de corretor de imóveis como perito e a definição da cobrança de honorários no exercício dessa função.

A pesquisa usou como metodologia a pesquisa bibliográfica, usando livros, artigos científicos e jurisprudência a respeito da temática proposta.

\section{O CORRETOR DE IMÓVEIS COMO PERITO AVALIADOR JUDICIAL}

O corretor de imóveis é a pessoa que se insere profissionalmente nas transações imobiliárias, frente essa função afirma-se que o corretor de imóveis pode ser 
classificado como um conciliador que busca se unir às partes em torno do objetivo central que é o imóvel, nesse sentido aponta a Lei 6.530/78:

Art 3ำ Compete ao Corretor de Imóveis exercer a intermediação na compra, venda, permuta e locação de imóveis, podendo, ainda, opinar quanto à comercialização imobiliária.

Parágrafo único. As atribuições constantes deste artigo poderão ser exercidas, também, por pessoa jurídica inscrita nos termos desta lei.

É possível inferir da letra da lei o conceito de corretor de imóveis, logo, este se traduz em uma pessoa que atua na intermediação no processo de compra e venda, permuta ou locação de imóveis, desta feita, o corretor deve atuar ao lado de todas as partes interessadas no processo de comercialização imobiliária.

Ao se analisar a competência e exercício da função do contador é possível observar que este se diferencia do empregado, isso porque somente fará jus à comissão caso o negócio que esteja intermediando seja concluído, do contrário seu esforço e energia não serão remunerados. Notoriamente tal fato se distingue do conceito de empregado que será remunerado por todo seu esforço, dedicação, independente dos resultados alcançados, é o que explica Gagliano e Pamplona Filho (2012).

Portanto em uma definição objetiva do conceito de corretor de imóveis entende-se que é a pessoa que tem por objetivo a aproximação das partes em torno do imóvel e diante dessa aproximação e fechamento do acordo fará jus à comissão.

A normatização da profissão de corretor de imóveis se iniciou em meados dos anos 50 quando houve propostas para criação de regras para a avaliação dos terrenos, e assim a Associação Brasileira de Normas Técnicas - ABNT ficou responsável pela elaboração de tais regulamentações.

No ano de 1977 a ABNT criou a norma NB502 que se referia aos procedimentos de avaliação de imóveis, e em segui outras normas apareceram sucedendo esta primeira, nesse sentido: 
A partir de 1999, iniciou-se um profundo trabalho de revisão das normas de avaliações brasileiras, dentre elas, a NBR 5676-Avaliação de imóveis urbanos, em vigência desde 1989, sucessora da NB-502 (1977), primeira norma a tratar de avaliações de imóveis urbanos, e, até então, principal referência para as avaliações imobiliárias. $O$ desenvolvimento do trabalho, coordenado pela ABNT - Associação Brasileira de Normas Técnicas, envolveu, ao longo de muitos meses, discussões e grupos de estudos, presenciais e via internet, em que tomaram parte, Comitês da própria entidade, representantes dos setores ligados ao assunto, universidades e profissionais, além de ter sido disponibilizada em Consulta Pública, resultando em uma abrangente reformulação dos preceitos normativos que regem a avaliação de bens, inclusive contemplando assuntos como meio ambiente e patrimônio histórico, até então desconsiderados na regulamentação normativa. (ALMEIDA; SOARES, 2006, p.2).

E assim seguindo as modificações em julho de 2004 houve a edição da norma 14.653 que foi subdividia em partes que buscou unificar as normas anteriores e acrescentou outros temas e especificações, a respeito dessa nova norma:

A nova norma, NBR 14653, em vigência a partir de Julho/2004, sob o título geral "Avaliação de bens", agrega as diversas normas anteriores, que tratavam do tema independentemente e que agora encontram-se reunidas nas sete partes que a compõe (algumas ainda em fase de desenvolvimento e discussão), assim distribuídas: - Parte 1: Procedimentos gerais; - Parte 2: Imóveis urbanos; - Parte 3: Imóveis rurais; • Parte 4: Empreendimentos; • Parte 5: Máquinas, equipamentos, instalações e bens industriais em geral; • Parte 6: Recursos naturais e ambientais; - Parte 7: Patrimônios históricos. Dentre as muitas alterações implementadas na nova Norma, destaca-se como imediata e fundamental, a harmonização de conceitos e definições das diversas normas relativas a trabalhos de avaliações, sob um mesmo enfoque e nomenclatura, apresentada na Parte 1- Procedimentos gerais, para servir de referência a cada uma das seis partes, que tratam dos tópicos específicos. (ALMEIDA; SOARES, 2006, p.2).

É de se observar que essas normas buscaram consolidar de forma correta os conceitos que envolvem as atividades profissionais do ramo imobiliário, e que deve ser observados como requisitos obrigatórios para a avaliação de imóveis, tanto de forma extrajudicial como dentro do contexto judicial.

É dentro do campo judicial que grande celeuma se instalou no tocante aos profissionais corretores de imóveis que são responsáveis sim pela função de perito 
avaliador judicial, e para isso é necessário apenas que se esclareça a formação deste profissional, e assim resta pacificada a posição dentro do Conselho Federal de Engenharia e Agronomia - CONFEA é a de que o perito avaliador de imóveis é o corretor de imóveis, posição essa que tem sido contrariada dentro dos tribunais, que constantemente contestam o seu direito ao recebimento de honorários.

Ressalte-se a importância de se falar a respeito da formação do profissional perito avaliador de imóveis, sabe-se que existem duas formações atualmente no campo de atuação do corretor de imóveis, assim tem-se o curso técnico em transação imobiliária que é mais célere, dura em média de 800 a 1200 horas e pode ser realizado por meio de ensino a distância; tem-se ainda o curso de gestão imobiliária que é um curso superior com duração de dois anos.

Logo, para o corretor que fez o curso técnico a atuação como perito avaliador deve estar condicionada à realização de um curso de avaliações, e assim obter sua inscrição no Cadastro Nacional de Avaliadores de Imóveis - CNAI, já para o corretor que se formou no curso de gestão de negócios imobiliários não existe nenhum entrave para sua atuação como perito avaliador, devendo constar do CNAI.

A respeito dos peritos há que se analisar o disposto no Código de Processo Civil de 2015:

Art. 156. O juiz será assistido por perito quando a prova do fato depender de conhecimento técnico ou científico.

$\S 1^{0}$ Os peritos serão nomeados entre os profissionais legalmente habilitados e os órgãos técnicos ou científicos devidamente inscritos em cadastro mantido pelo tribunal ao qual o juiz está vinculado.

$\S 2$ Para formação do cadastro, os tribunais devem realizar consulta pública, por meio de divulgação na rede mundial de computadores ou em jornais de grande circulação, além de consulta direta a universidades, a conselhos de classe, ao Ministério Público, à Defensoria Pública e à Ordem dos Advogados do Brasil, para a indicação de profissionais ou de órgãos técnicos interessados. 
$\S 3^{\circ}$ Os tribunais realizarão avaliações e reavaliações periódicas para manutenção do cadastro, considerando a formação profissional, a atualização do conhecimento e a experiência dos peritos interessados.

§ 4ํㅗ Para verificação de eventual impedimento ou motivo de suspeição, nos termos dos arts. 148 e 467 , o órgão técnico ou científico nomeado para realização da perícia informará ao juiz os nomes e os dados de qualificação dos profissionais que participarão da atividade.

$\S 5^{\circ} \mathrm{Na}$ localidade onde não houver inscrito no cadastro disponibilizado pelo tribunal, a nomeação do perito é de livre escolha pelo juiz e deverá recair sobre profissional ou órgão técnico ou científico comprovadamente detentor do conhecimento necessário à realização da perícia.

Observa-se que a determinação do códex é a necessidade de regular inscrição em cadastro mantido pelo tribunal, ou ainda por livre escolha do juiz dentre profissionais regularmente habilitados, assim, o corretor inscrito regularmente no CNAI pode ser perito avaliador judicial.

Assim há que se observar jurisprudência a respeito do assunto:

AGRAVO DE INSTRUMENTO. AÇÃO DE CONSTITUIÇÃO DE SERVIDÃO ADMINISTRATIVA. APURAÇÃO DO REAL VALOR DEVIDO A TÍTULO DE JUSTA INDENIZAÇÃO. PERÍCIA REALIZADA POR CORRETOR DE IMÓVEIS ACOMPANHADO POR ENGENHEIRO CIVIL. SUBSTITUIÇÃO. DESCABIMENTO. A substituição do perito é possível quando o perito não possuir conhecimento técnicos ou científicos suficientes para trazer esclarecimentos necessários aos autos. Ademais, o perito não está obrigado a adotar a técnica ou o instrumento que uma das partes julga mais adequados, desde que explicite os padrões e parâmetros oficiais por ele utilizados, tal como ocorreu nos autos. RECURSO NÃO PROVIDO. AGRAVO INTERNO. INTERPOSIÇÃO CONTRA DECISÃO INAUGURAL PROFERIDA NO AGRAVO DE INSTRUMENTO QUE NÃO CONCEDEU O PEDIDO DE ANTECIPACCÃO DE TUTELA RECURSAL. PREJUDICADO ANTE O JULGAMENTO DO PRIMEIRO RECURSO. IDÊNTICAS RAZÕES SUSTENTADAS EM AMBOS OS RECURSOS. RECURSO PREJUDICADO.

(TJPR - 5a C. Cível - 0047162-09.2019.8.16.0000 - Guarapuava - Rel.: Desembargador Carlos Mansur Arida - Rel.Desig. p/ o Acórdão: Desembargador Nilson Mizuta - J. 03.03.2020) 
Nota-se então que o perito corretor de imóveis, ao possuir sua regular inscrição no órgão e conhecimento técnico pode atuar como perito avaliador judicial.

\section{CADASTRO E CONDIÇÕES PARA A INSCRIÇÃO NO CNAI}

Já restou claro que o corretor de imóveis que desejar atuar como, assim o laudo de avaliação que é denominado pelo Conselho Federal de Corretores de ImóveisCOFECI como Parecer técnico de Avaliação Mercadológica - PTAM e deve estar inscrito no CNAI que somente aceita a inscrição de corretores de imóveis devidamente inscritos no CRECI.

Como requisito o corretor que possui apenas o curso técnico em transações imobiliárias deve realizar o curso de avaliação imobiliária que é promovida por entidades certificadas e reconhecidas pelo COFECI, já para os corretores que fizerem o curso superior de Gestão de Negócios Imobiliários apenas deve ocorrer a regular inscrição no CNAI.

Nesse escopo, para a efetiva inscrição no CNAI deve: ser corretor de imóveis se for formado em curso que cumpra as exigências da resolução 1.066/2007 do COFECl a inscrição no CNAI ocorre de forma automática; se for formado em curso técnico deve apresentar o certificado de conclusão do curso em avaliação imobiliária.

\section{O CORRETOR COMO PERITO DO JUÍZO E SUAS ATRIBUIÇÕES}

Com a devida inscrição no CNAl o corretor de imóveis pode começar a atuar como perito avaliador judicial, e assim deve possuir profundo conhecimento técnico, ser especialista no assunto, uma vez que ao atuar será a pessoa de confiança do juiz na elaboração de um laudo técnico.

Os processos de execução na legislação pátria são fundados na penhora de bens, e para isso se faz necessária à devida avaliação do bem judicializado, com análise de suas características e definição dos corretos valores do imóvel. 
Nessa senda o perito judicial deve possuir conhecimento dos procedimentos judiciais em que atua, além de diversas habilidades dentro do seu campo técnico, dominando as questões técnicas que exijam a atenção do perito avaliador, atuando de forma imparcial, elaborando um PTAM completo, claro e fundamentado de forma técnica.

Ao ser nomeado o perito deve ter acesso aos autos para que possa avaliar e apresentar sua proposta de honorários, e a partir daí as partes devem se manifestar a respeito dos honorários periciais, com a devida concordância as partes realizam o depósito inicial que deve ser liberado por meio de alvará a condição de 50\% dos honorários de forma a cobrir os custos iniciais para a elaboração do laudo técnico de avaliação.

Além da elaboração do laudo pericial técnico o perito avaliador deve responder aos quesitos elaborados pelas partes envolvidas no litígio, assim ao entregar o laudo o perito ainda pode ser intimado para prestar os devidos esclarecimentos e ao final pode solicitar a liberação dos honorários restantes.

A elaboração do laudo pericial exige técnica e conhecimento, isso porque prevê o Código de Processo Civil em seu artigo 873, III a possibilidade de ser o laudo pericial anulado por terem as partes apresentados de forma fundamentada divergências de valores, ou ainda o juiz discordar e tiver fundada dúvida a respeito do valor apresentado pelo perito avaliador, daí a necessidade do profundo conhecimento técnico que se exige do corretor de imóveis atuando na função de perito avaliador.

\section{DO LAUDO PERICIAL E SUA ELABORAÇÃO}

Muito se falou em laudo pericial, que na verdade se constitui de um relatório onde o perito avaliador deve apresentar o resultado de seu trabalho, apontando para suas observações, respondendo aos quesitos e apontando para as conclusões de acordo com as informações colhidas durante o trabalho pericial.

Nesse sentido: 
O laudo tem de se fundamentado, demonstrando o perito os métodos de que se serviu para elucidar a questão posta para seu estudo. Por exemplo, se de perícia técnica grafoscópica se tratar, deve indicar os critérios para afirmar a coincidência ou a disparidade entre as letras postas para seu exame, no que toca aos pontos convergentes e divergentes da gênese e o ataque da grafia; se a perícia for médica ou de engenharia, deve individualizar a situação do objeto posto para seu exame, identificando suas características, as razões de seu diagnóstico, as constatações a respeito das quais a causa é ou não identificada, os métodos técnicos e científicos a que se serviu e, se possível, a corrente de pensamento a que se socorreu, em caso de dúvida da ciência para cientificação do caso. (NERY JR, 2003, p.47).

Destaca-se, por oportuno, que os laudos periciais devem ser elaborados de forma objetiva, observando o rigor técnico, focado em exatidão e clareza das informações prestadas, nesse sentido coerente explicação:

Agora os corretores de imóveis podem fixar o valor mercadológico de um imóvel, responsabilidade que antes era só dos arquitetos e engenheiros. O Cofeci (Conselho Federal de Corretores de Imóveis) regulamentou a competência ao corretor imobiliário, através da resolução 957 de 2006, para produzir parecer técnico de avaliação de um imóvel, legalizando tal atividade. Márcio Almeida (2016), presidente do CRECI-MG, elucida que a já era definido pela lei 6530 de 1978 a competência do corretor para opinar a respeito do valor de comercialização de imóveis, apesar dos critérios não serem estipulados para que o parecer técnico de avaliação fosse elaborado para a avaliação mercadológica. O Cofeci, com sua resolução, além de definir os requisitos basilares do documento, previu a necessária formação necessária para que o corretor possa exercer esta atividade. (DANTAS, 2017, p.12).

A elaboração de um laudo pericial técnico passa pelo conhecimento do perito do processo em questão, logo o perito deve se debruçar sobre o litígio, buscando compreender todos os detalhes, inclusive solicitando esclarecimentos de operador do direito quando surgirem dúvidas jurídicas.

Há que se compreender as etapas que devem constituir o trabalho do perito avaliador:

Em um enfoque simplificado e objetivo, uma avaliação de imóvel pode ser decomposta em três etapas fundamentais. As duas primeiras, compõem os trabalhos de campo, alicerce fundamental de qualquer avaliação, e sobre o qual estará assentada a base de todos os resultados e conclusões, e a última, refere-se aos trabalhos de escritório, que cuida 
da análise e tratamento dos dados obtidos nas duas etapas anteriores e que podem assim ser resumidas: $1^{a}$ ) vistoria: ações executadas para o levantamento de todas as características do bem a avaliar; $2^{\underline{a}}$ ) pesquisa de mercado: trabalhos de coleta de preços para a identificação do valor corrente; $3^{a}$ ) relatório final: apresentação organizada dos resultados e das conclusões do trabalho. Cada uma destas etapas será abordada a seguir em seus aspectos principais, para que se tenha uma visão de conjunto de uma avaliação de imóvel. (ALMEIDA; SOARES, 2006, p.3).

A vistoria deve ser marcada pelo perito e acompanhada pelas partes e podem ser marcadas quantas vistorias forem necessárias para a análise de toda a estrutura física do imóvel objeto de avaliação, na sequencia a depender da metodologia empregada pelo perito avaliador o mesmo pode realizar uma pesquisa de mercado com a intenção de comparar os imóveis, constituição e valores dos mesmos para a elaboração do relatório final, onde constaram as conclusões encontradas pelo perito avaliador.

O documento elaborado pelo perito avaliador deve ser documentado no $\mathrm{CRECI}$ onde receberá um selo para cada documento e que deve necessariamente constar no laudo elaborado pelo perito avaliador. (DANTAS, 2017).

Importante ainda destacar que o perito deve dispor de todos os meios que possam facilitar a correta e clara compreensão dos motivos ensejadores de suas conclusões, podendo lançar mão de gráficos, fotografias, enfim todos os documentos necessários para a compreensão do laudo técnico elaborado.

\section{DO CABIMENTO DOS HONORÁRIOS E SUA PRECIFICAÇÃO/CÁLCULO}

É salutar ressaltar que o perito avaliador corretor de imóveis não possui uma tabela que define a cobrança de honorários, dessa forma fica a critério do corretor a definição dos valores cobrados, devendo ser analisado o caso concreto para que sejam arbitrados honorários justos e compatíveis com o trabalho a ser desempenhado pelo avaliador judicial. 


\section{TENTATIVA DE IMPUGNAÇÃO DOS HONORÁRIOS}

Diante da complexidade do caso em litígio o juiz deve nomear perito para a realização da avaliação do bem, caso não seja necessário o próprio oficial de justiça pode realizar a avaliação de bens, todavia ao se falar de bens imóveis a presença de um perito avaliador se faz necessária, utilizando todo seu conhecimento técnico para a elaboração do PTAM.

Ao ser nomeado um perito avaliador judicial o mesmo tem o direito ao recebimento de honorários periciais para a realização do trabalho a ele solicitado, como já informado o corretor de imóveis não possui uma tabela como valores pré-definidos que deve seguir, logo, inúmeros são os casos em que as partes buscam impugnar os valores cobrados pelos peritos judiciais, ou por entenderem estar em desacordo com o valor da causa, ou ainda por entenderem que o corretor de imóveis não pode atuar como perito avaliador.

Há casos onde as partes do processo tentam impugnar os honorários do perito por acharem altos os valores cobrados sem levar em conta a complexidade da avaliação e a proporcionalidade em relação ao valor da causa, ou por achar que o corretor de imóveis não pode exercer a função de perito avaliador, discussões essas onde já temos jurisprudência a favor do corretor de imóveis perito avaliador:

AGRAVO DE INSTRUMENTO. DECISÃO QUE INDICA CORRETOR DE IMÓVEIS PARA ELABORAR PERÍCIA SOBRE AVALIAÇÃO DE LOCAÇÃO. REQUERIMENTO DA PROVA TÉCNICA POR AMBAS AS PARTESS. HONORÁRIOS PERICIAIS EM PROPORÇÃO IGUALITÁRIA. RECURSO PARCIALMENTE PROVIDO. 1. Cuida-se de agravo de instrumento oposto em face de decisão que nomeou um corretor de imóveis para realizar a perícia na ação de renovação de locação de imóveis e determinou que os honorários periciais sejam suportados apenas pelo agravante. 2. O conteúdo do art. 95, CPC permite concluir que a remuneração do perito será paga pela parte que requereu. Em sendo o caso de as duas partes se manifestarem pela produção da prova pericial, nada mais justo que as despesas da perícia sejam custeadas pelos requerentes. 3. De acordo com previsão normativa, mais especificamente 0 art. $3^{\circ}$ da Lei $6.530 / 78$, que regula a profissão do corretor de imóveis, dentre as atribuições desse profissional, está a emissão de opinião sobre a comercialização imobiliária. Assim, por 
simples leitura da lei regulamentadora da profissão, já se deve afastar o argumento do recorrente no sentido de que esse tipo de perícia é de atribuição exclusiva dos profissionais da engenharia civil. 4. A indicação do valor do aluguel de um imóvel depende, principalmente, do conhecimento da situação do mercado imobiliário local e das características particulares do imóvel, mostrando-se, portanto, mais apto, nesse particular, o corretor imobiliário por ser profissional que atua diariamente nesse mercado, do que propriamente os profissionais da engenharia que têm seu campo de atuação diverso da seara do corretor. 5. Recurso parcialmente provido. (TJDFT AGRAVO DE INSTRUMENTO 0702535-25.2019.8.07.0000, DJ 05/06/2019).

Nota-se que a decisão exarada acima aponta para o fato de que os corretores de imóveis podem atuar como peritos avaliadores, e até mesmo sua comprovada capacidade técnica se mostra hábil para a elaboração de laudo pericial técnico de avaliação de imóveis, logo, não há que se falar em impugnação de honorários periciais diante da correta atuação do perito avaliador.

Os valores de honorários periciais devem observar o grau de dificuldade do trabalho realizado pelo perito avaliador, de forma a guardar correta relação entre o valor do imóvel avaliado e o trabalho técnico realizado.

\section{CONCLUSÃO}

Ao fim do estudo foi possível entender a função do corretor de imóveis que atua como perito avaliador judicial, de tal maneira que se compreende que o profissional deve possuir profundo conhecimento técnico, ter domínio do mercado, além da regular inscrição no $\mathrm{CRECl}$ e CNAI, para então atuar como perito judicial.

As habilidades técnicas do perito judicial não devem se ater ao profissional de engenharia, sabe-se que em muitos casos o corretor de imóveis tem mais conhecimento a respeito dos valores de imóveis e do mercado de venda de imóveis da região do que o próprio profissional de engenharia.

Logo, percebe-se pela determinação do Código de Processo Civil que a exigência do perito avaliador se encontra no seu conhecimento técnico e habilidades para a correta 
elaboração de PTAM claro, objetivo e com as devidas informações prestadas que possam embasar a decisão judicial.

\section{REFERÊNCIAS}

ABNT NBR 14653-4. Avaliação de bens Parte 4: Empreendimentos. Rio de Janeiro, 2002.

ABNT, NBR 14.653-1. Avaliação de Bens, Parte 1: Procedimentos Gerais. Rio de Janeiro, 2001.

ABNT, NBR 14.653-1. Avaliação de Bens, Parte 2 - Imóveis Urbanos. Rio de Janeiro, 2004a.

ABNT, NBR 14.653-1. Avaliação de Bens, Parte 3 - Imóveis rurais. Rio de Janeiro, 2004b.

ALMEIDA, Carlos Augusto de; SOARES, Carlos Alberto Pereira. A vistoria do imóvel em face da nova norma ABNT 14653. IBAPE - XXII UPAV / XIII COBREAP FORTALEZA/CE - ABRIL/2006.

DANTAS, Thiago Pereira. Avaliação Imobiliária e sua Elaboração por Corretores de Imóveis para Fins de Perícia. Revista Científica Multidisciplinar Núcleo do Conhecimento. Ano 02, Vol. 16. pp 364-380. Março de 2017. ISSN:2448-0959.

GAGLIANO, Pablo Stolze; PAMPLONA FILHO, Rodolfo. Novo curso de direito civil, volume III: responsabilidade civil. 9 ed. rev. e atual. São Paulo: Saraiva, 2012.

NERY JUNIOR, Nelson. Código de Processo civil comentado: e legislação extravagante. 7 ed. rev. e ampliada São Paulo, Editora Revista dos Tribunais, 2003.

TJ-PR, AGRAVO DE INSTRUMENTO no 0047162-09.2019.8.16.0000 - 5a Câmara Cível, Rel. Nilson Mizuta, DJe de 10/03/2020. Disponível em: <http://portal.tjpr.jus.br/jurisprudencia/j/4100000010989241/Ac\%C3\%B3rd\%C3\%A3o -0047162-09.2019.8.16.0000\#>. Acesso em: 20 jul.2020. 
TJ-DF. 0702535-25.2019.8.07.0000, Relator: Gilberto de Oliveira, Data de Julgamento: 05/06/2019. Disponível em: $<$ https://pesquisajuris.tjdft.jus.br/IndexadorAcordaos-web/sistj>. Acesso em: 20 jul.2020.

Enviado: Outubro, 2019.

Aprovado: Agosto, 2020. 